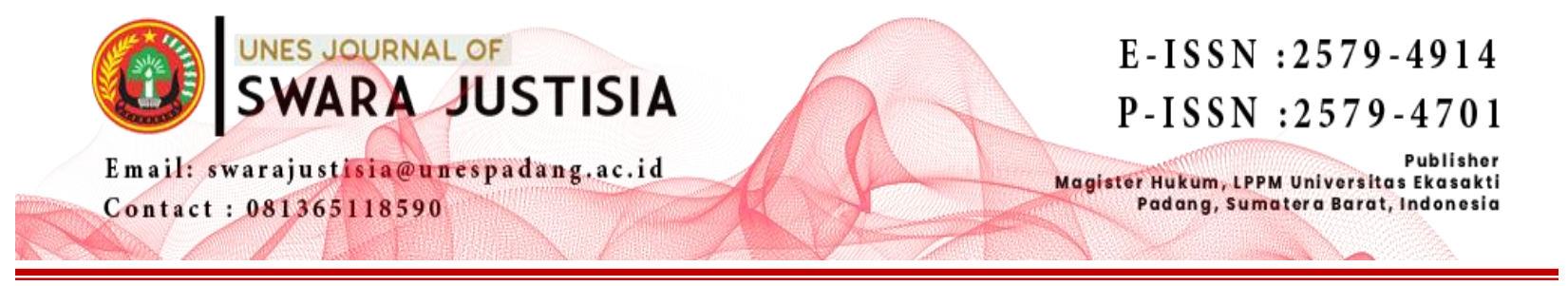

\title{
PELAKSANAAN EKSEKUSI TERHADAP BARANG JAMINAN YANG TIDAK MEMILIKI AKTA FIDUSIA BERDASARKAN PUTUSAN NO. REG. 81/Pdt.G/2018.PN.Pdg
}

\author{
Dora Tiara $^{1)}$, Naldi Gantika ${ }^{2)}$ \\ ${ }^{1)}$ Fakultas Hukum,Universitas Ekasakti, Padang, Indonesia \\ Email: doraeljaber@gmail.com \\ ${ }^{2)}$ Fakultas Hukum,Universitas Ekasakti, Padang, Indonesia \\ Email: hgantika74@gmail.com
}

\begin{abstract}
Financial institutions and banks provide financing for consumers, leasing, factoring. They generally use the procedure of the agreement which includes a fiduciary guarantee for fiduciary security objects. In practice, financial institutions provide movable goods requested by consumers. Consequently the debtor surrenders to the creditor in a fiduciary manner. Implementation of the executorial title by PT. Mandiri Tunas Finance is not through a court decision or fiduciary guarantee certificate, but only based on a power of attorney and agreement made by the collector. The sale of fiduciary collateral objects carried out by PT. Mandiri Tunas Finance does not go through public auctions but through separate sales; and Underhanded sales are not based on the agreement of both parties, the agreement is only based on PT. Mandiri Tunas Finance so that it harms the consumer. Actions taken by PT. Mandiri Tunas Finance does not provide legal certainty to both parties. The act of execution was carried out solely to safeguard assets regardless of legal certainty of the rights of consumers / debtors contained in fiduciary security objects in the form of car vehicles. Legal constraints of not registering the agreement are that execution cannot be carried out, based on Article 3 of the Minister of Finance Regulation No. 130 / PMK.010 / 2012 stating that finance companies are prohibited from withdrawing fiduciary objects in the form of motorized vehicles if the Fiduciary Registration Office has not issued a guarantee certificate fiduciary and hand it over to the finance company. With these provisions, PT. Mandiri Tunas Finance cannot execute if it does not register fiduciary collateral objects because without the registration of fiduciary collateral objects the fiduciary guarantee certificate cannot be issued.
\end{abstract}

Keywords: Collateral, Fiduciary Deed.

ABSTRAK
Lembaga pembiayaan dan bank menyelenggarakan pembiayaan bagi konsumen, sewa guna usaha, anjak piutang. Mereka umumnya menggunakan tata cara perjanjian yang mengikutkan adanya jaminan fidusia bagi objek benda jaminan fidusia. Prakteknya lembaga pembiayaan menyediakan barang bergerak yang diminta konsumen. Konsekuensinya debitur menyerahkan 
kepada kreditur secara fidusia. Pelaksanaan titel eksekutorial oleh PT. Mandiri Tunas Finance tidak melalui putusan pengadilan ataupun sertifikat jaminan fidusia melainkan hanya berdasarkan atas surat kuasa dan surat perjanjian yang dilakukan oleh pihak collector. Penjualan benda objek jaminan fidusia yang dilakukan PT. Mandiri Tunas Finance tidak melalui pelelangan umum melainkan penjualan tersendiri; dan Penjualan di bawah tangan yang dilakukan tidak berdasarkan kesepakatan kedua belah pihak, kesepakatan itu hanya berdasarkan atas dari pihak PT. Mandiri Tunas Finance sehingga merugikan pihak konsumen. Tindakan yang dilakukan oleh pihak PT. Mandiri Tunas Finance tidak memberikan kepastian hukum kepada kedua belah pihak. Tindakan eksekusi tersebut dilakukan hanya semata-mata untuk mengamankan aset tanpa menghiraukan kepastian hukum terhadap hak-hak konsumen/debitur yang terdapat dalam benda jaminan fidusia berupa kendaraan mobil. Kendala-kendala hukum dari tidak didaftarkannya perjanjian tersebut adalah tidak bisa dilakukannya eksekusi, berdasarkan Pasal 3 Peraturan Menteri Keuangan Nomor 130/PMK.010/2012 menyebutkan bahwa perusahaan pembiayaan dilarang melakukan penarikan benda jaminan fidusia berupa kendaraan bermotor apabila Kantor Pendaftaran Fidusia belum menerbitkan sertifikat jaminan fidusia dan menyerahkannya kepada perusahaan pembiayaan. Dengan ketentuan tersebut maka PT. Mandiri Tunas Finance tidak dapat melakukan eksekusi apabila tidak mendaftarkan benda jaminan fidusia karena tanpa terdaftarnya benda jaminan fidusia maka sertifikat jaminan fidusia tidak dapat diterbitkan.

Kata Kunci: Jaminan, Akta Fidusia.

\section{PENDAHULUAN}

Eksistensi Fidusia sebagai pranata jaminan diakui berdasarkan yurisprudensi. Konsistensi fidusia berdasarkan yurisprudensi yang pernah ada adalah penyerahan hak milik secara kepercayaan atas kebendaan atau barang-barang bergerak (untuk debitur) kepada kreditur dengan penguasaan fisik atas barang-barang itu tetap pada kreditur dengan ketentuan bahwa jika debitur melunasi hutangnya sesuai dengan jangka waktu yang telah ditetapkan atau tanpa cidera janji maka kreditur berkewajiban untuk mengembalikan hak milik atas barang- barang tersebut kepada debitur (contribution processorium).

Perjanjian fidusia adalah perjanjian hutang piutang kreditur kepada debitur yang melibatkan penjaminan. Jaminan tersebut kedudukannya masih dalam penguasaan pemilik jaminan. Praktek fidusia telah lama dikenal sebagai salah satu instrumen jaminan kebendaan bergerak yang bersifat non-possessory. Berbeda dengan jaminan kebendaan bergerak yang bersifat possessory, seperti gadai, jaminan fidusia memungkinkan debitur bersifat sebagai pemberi jaminan untuk tetap menguasi dan menggambil manfaat atas benda bergerak yang telah dijaminkan tersebut.

Undang-Undang Nomor 42 Tahun 1999 Tentang Jaminan Fidusia, keberadaan praktek fidusia di Indonesia dilandaskan kepada yurisprudensi dari Hoge Raad Belanda yang dikenal putusan Bier Broumerji Arrest, dimana hakim untuk pertama kali mengesahkan adanya mekanisme penjaminan seperti tersebut. Sebelum Undang-Undang Noomor 42 Tahun 1999 Tentang Jaminan Fidusia, sedikit sekali panduan yang dapat dipegang sebagai referensi bagi keberlakuan instrumen fidusia. Ada juga beberapa ketentuan perundang-undangan yang 
menyinggung fidusia sebagai suatu instrument jaminan. Meskipun begitu, secara umum tidak ada panduan teknis mengenai pelaksanaan instrumen fidusia tersebut. Lahirnya jaminan fidusia merupakan murni didasarkan pada ketentuan Pasal 1320 jo. 1338 Kitab Undang- Undang Hukum Perdata mengenai kebebasan berkontrak.

Tidak ada satu standar buku mengenai syarat formal penjaminan fidusia. Juga tidak ada feature lain yang umumnya terdapat suatu instrument jaminan. Tidak ada hak prioritas yang dimiliki oleh kreditur penerima fidusia. Lebih fatal lagi, tidak ada institusi pendaftaran yang bertanggung jawab untuk melakukan pencatatan terhadap setiap pembebanan fidusia, sehingga pada masa itu fidusia benar-benar merupakan instrumen yang kurang dapat diandalkan dimata para kreditur.

Pada saat ini jaminan yang sering digunakan di dalam praktek adalah Jaminan Fidusia, oleh karena Lembaga Jaminan Fidusia adalah jaminan atas benda bergerak yang banyak diminati oleh masyarakat bisnis. Pembinaan hukum terhadap bidang hukum jaminan adalah sebagai konsekuensi logis dan merupakan perwujudan tanggung jawab dari pembinaan hukum mengimbangi lajunya kegiatan-kegiatan dalam bidang perdagangan, perindustrian, perseroan, pengangkutan, dan kegiatan-kegiatan dalam proyek pembangunan (Sri Soedewi Masjchoen Sofwan, 2007:1).

Selama ini sebelum keluarnya Undang-Undang Nomor 42 Tahun 1999 tentang Jaminan Fidusia, tidak ada kejelasan mengenai bagaimana caranya mengeksekusi obyek jaminan fidusia. Karena tidak ada ketentuan yang mengaturnya, banyak yang menafsirkan eksekusi obyek jaminan fidusia dengan memakai prosedur gugatan biasa (lewat pengadilan dengan prosedur biasa) yang panjang, dan melelahkan. Walaupun sejak berlakunya Undang- Undang Nomor 16 Tahun 1985 tentang Rumah Susun, ada prosedur yang lebih mudah lewat eksekusi dibawah tangan. Disamping syaratnya yang berat, eksekusi obyek jaminan fidusia dibawah tangan tersebut tentunya hanya berlaku atas fidusia yang berhubungan dengan rumah susun saja. Oleh karena itu, dalam praktek hukum, eksekusi fidusia dibawah tangan sangat jarang dilakukan (Sri Soedewi Masjchoen Sofwan, 1982:229).

\section{METODE PENELITIAN}

Sumber data yang digunakan yaitu data sekunder dan data primer. Data Sekunder diperoleh melalui studi dokumen atau dengan penelitian kepustakaan sehingga diperoleh data awal untuk menunjang pelaksanaan penelitian di lapangan. Sedangkan data primer melalui studi lapangan dengan teknik wawancara kepada nara sumber ataupun informan yang berkaitan dengan objek penelitian. Data-data tersebut dianalisis secara kualitatif dan disajikan dalam bentuk deskriptif. 


\section{HASIL DAN PEMBAHASAN}

\section{A. Bagaimana Pelaksanaan Eksekusi Terhadap Barang Jaminan Yang Tidak Memiliki Akta Fidusia Berdasarkan Putusan No. Reg. 81/Pdt.G/2018.PN.Pdg}

Berdasarkan analisis penulis pada prakteknya eksekusi yang dilakukan oleh PT. Mandiri Tunas Finance, yaitu:

1. Pelaksanaan titel eksekutorial oleh PT. Mandiri Tunas Finance tidak melalui putusan pengadilan ataupun sertifikat jaminan fidusia melainkan hanya berdasarkan atas surat kuasa dan surat perjanjian yang dilakukan oleh pihak collector;

2. Penjualan benda objek jaminan fidusia yang dilakukan PT. Mandiri Tunas Finance tidak melalui pelelangan umum melainkan penjualan tersendiri; dan

3. Penjualan di bawah tangan yang dilakukan tidak berdasarkan kesepakatan kedua belah pihak, kesepakatan itu hanya berdasarkan atas dari pihak PT. Mandiri Tunas Finance sehingga merugikan pihak konsumen.

Menurut keterangan wawancara penggugat (Robby Octo Irawan), pada tahap eksekusi yang dilakukan pihak PT. Mandiri Tunas Finance melakukan eksekusi benda jaminan fidusia tidak memperlihatkan sertifikat jaminan fidusia dan juga tidak adanya juru sita ataupun pelelangan umum sebagaimana yang diatur dalam Undang-Undang Jaminan Fidusia. Pihak kreditur melakukan eksekusi benda jaminan fidusia melalui jasa colector, pihak colector melakukan eksekusi jaminan fidusia tanpa memperlihatkan sertifikat jaminan fidusia. Berdasarkan hasil wawancara dengan staff legal PT. Mandiri Tunas Finance, diketahui bahwa dalam pelaksanaan penyitaan barang jaminan oleh PT. Mandiri Tunas Finance dilakukan oleh pegawai PT. Mandiri Tunas Finance yang ditunjuk sebagai collector. Penyitaan itu berdasarkan surat kuasa penarikan yang ditanda tangani oleh konsumen/debitur. Pihak PT. Mandiri Tunas Finance tidak pernah melakukan penyitaan terhadap benda jaminan fidusia berdasarkan putusan atau penetapan dari pengadilan, serta penyitaan yang dilakukan oleh pihak PT. Mandiri Tunas Finance hanya dilakukan collector tanpa ada keterlibatan juru sita pengadilan terhadap objek sengketa berupa kendaraan mobil yang menjadi objek jaminan fidusia.

Tindakan yang dilakukan oleh pihak PT. Mandiri Tunas Finance tidak memberikan kepastian hukum kepada kedua belah pihak. Tindakan eksekusi tersebut dilakukan hanya semata-mata untuk mengamankan aset tanpa menghiraukan kepastian hukum terhadap hakhak konsumen/debitur yang terdapat dalam benda jaminan fidusia berupa kendaraan mobil. Dalam jaminan berupa kendaraan tersebut terdapat hak kedua belah pihak baik konsumen ataupun pihak perusahaan, sehingga eksekusi tersebut harus mempertimbangkan hak masing-masing pihak, serta eksekusi yang dilakukan oleh pihak PT. Mandiri Tunas Finance tidak sesuai dengan prosedur hukum yang berlaku. 


\section{B. Apa Kendala-kendala Dalam Pelaksanaan Eksekusi Terhadap Barang Jaminan Yang Tidak Memiliki Akta Fidusia Berdasarkan Putusan No. Reg. 81/Pdt.G/2018.PN.Pdg}

Berdasarkan hasil wawancara dengan Pelayanan Administrasi Hukum Umum dan Kekayaan Intelektual, diketahui bahwa dalam pendaftaran jaminan fidusia apabila perusahaan tidak mendaftarkan benda jaminan fidusia paling lama 30 (tiga puluh) hari kalender terhitung sejak tanggal perjanjian pembiayaan konsumen, maka sertifikat jaminan fidusia tidak dapat dibuatkan dan perjanjian tambahan benda jaminan fidusia secara hukum batal. Hal ini dikarenakan perjanjian yang jaminannya atas benda jaminan fidusia wajib didaftarkan, apabila tidak didaftarkan maka secara tidak langsung perjanjian tersebut bukan perjanjian fidusia.

Mengenai pendaftaran jaminan fidusia yang dilakukan oleh lembaga pembiayaan konsumen, untuk itu penulis melakukan penelitian terhadap konsumen untuk megetahui apakah konsumen mengetahui bahwa benda jaminan fidusia yang dibiayai oleh lembaga pembiayaan konsumen wajib didaftarkan.

Permasalahan yang terjadi pada PT. Mandiri Tunas Finance selaku kreditur dan Robby Octo Irawan selaku debitur, PT. Mandiri Tunas Finance melakukan eksekusi terhadap benda jaminan fidusia dengan atas dasar Robby Octa Irawan lalai dalam melakukan prestasi yaitu terlambatnya dalam pembayaran kredit, sementara perjanjian pembiayaan konsumen antara PT. Mandiri Tunas Finance dengan Robby Octo Irawan tidak didaftarkan, sehingga yang melakukan tindakan wanprestasi bukan hanya terdapat pada Robby Octa Irawan saja, ternyata pihak PT. Mandiri Tunas Finance juga melakukan tindakan wanprestasi dalam bentuk tidak mendaftarkan perjanjian tersebut ke Kantor Pendaftaran Fidusia.

Untuk itu penulis melakukan penelitian terhadap konsumen untuk mengetahui apakah konsumen mengetahui apa kendala-kendala hukum terhadap perjanjian jaminan fidusia yang tidak didaftarkan terutama masalah eksekusi apabila terjadi wanprestasi. Kendala-kendala hukum dari tidak didaftarkannya perjanjian tersebut adalah tidak bisa dilakukannya eksekusi, berdasarkan Pasal 3 Peraturan Menteri Keuangan Nomor 130/PMK.010/2012 menyebutkan bahwa perusahaan pembiayaan dilarang melakukan penarikan benda jaminan fidusia berupa kendaraan bermotor apabila Kantor Pendaftaran Fidusia belum menerbitkan sertifikat jaminan fidusia dan menyerahkannya kepada perusahaan pembiayaan. Dengan ketentuan tersebut maka PT. Mandiri Tunas Finance tidak dapat melakukan eksekusi apabila tidak mendaftarkan benda jaminan fidusia karena tanpa terdaftarnya benda jaminan fidusia maka sertifikat jaminan fidusia tidak dapat diterbitkan.

\section{KESIMPULAN DAN SARAN}

1. Pelaksanaan titel eksekutorial oleh PT. Mandiri Tunas Finance tidak melalui putusan pengadilan ataupun sertifikat jaminan fidusia melainkan hanya berdasarkan atas surat kuasa dan surat perjanjian yang dilakukan oleh pihak collector. Penjualan benda objek jaminan fidusia yang dilakukan PT. Mandiri Tunas Finance tidak melalui pelelangan umum melainkan penjualan tersendiri; dan tidak berdasarkan kesepakatan kedua belah pihak, 
kesepakatan itu hanya berdasarkan atas dari pihak PT. Mandiri Tunas Finance sehingga merugikan pihak konsumen. Tindakan yang dilakukan oleh pihak PT. Mandiri Tunas Finance tidak memberikan kepastian hukum kepada kedua belah pihak. Tindakan eksekusi tersebut dilakukan hanya semata-mata untuk mengamankan aset tanpa menghiraukan kepastian hukum terhadap hak-hak konsumen/debitur yang terdapat dalam benda jaminan fidusia berupa kendaraan mobil.

2. Kendala-kendala hukum dari tidak didaftarkannya perjanjian tersebut adalah tidak bisa dilakukannya eksekusi, berdasarkan Pasal 3 Peraturan Menteri Keuangan Nomor 130/PMK.010/2012 menyebutkan bahwa perusahaan pembiayaan dilarang melakukan penarikan benda jaminan fidusia berupa kendaraan bermotor apabila Kantor Pendaftaran Fidusia belum Penjualan di bawah tangan yang dilakukan menerbitkan sertifikat jaminan fidusia dan menyerahkannya kepada perusahaan pembiayaan. Dengan ketentuan tersebut maka PT. Mandiri Tunas Finance tidak dapat melakukan eksekusi apabila tidak mendaftarkan benda jaminan fidusia karena tanpa terdaftarnya benda jaminan fidusia maka sertifikat jaminan fidusia tidak dapat diterbitkan.

\section{DAFTAR PUSTAKA}

Ade Sofyan Mulazid, Kedudukan Sistem Pengadaian Syariah Dalam Sistem Hukum Nasional Di Indonesia. Kementerian Agama RI, 2012.

C.S.T. Kansil, Christine C.S.T. Kansil, Pokok-pokok Etika Profesi Hukum, Cet. ke 3, Pradnya Paramita, Jakarta, 2006.

Sayyid Sabiq, Fikih Sunnah 5. Cakrawal Publishing, Jakarta, 2009.

Sri Soedewi Masjchoen Sofwan, Himpunan Karya Tentang Hukum jaminan, Liberty, Yogyakarta, 1982.

Sri Soedewi Masjchoen Sofwan, Hukum Jaminan Di Indonesia Pokok pokok Hukum Jaminan dan Jaminan perorangan, Liberty, Yogyakarta, 2007

Sutan Remi Syahdeini, Perbankan Islam dan Kedudukannya dalam Tata Hukum Perbankan. Pustaka Ulama Grafiti, Jakarta, 1999. 